Web Jurnal:

http://ejournal.kemenperin.go.id/jli

\title{
Pengaruh pemlastis dioktil ftalat terhadap sifat fisis dan mekanis kulit sintetis
}

\section{Effect of dioctyl phtalate plasticizer on physical and mechanical properties of synthetic leather}

\author{
Muhammad Sholeh* dan Siti Rochani \\ Balai Besar Kulit, Karet, dan Plastik \\ Jl. Sokonandi No. 9 Yogyakarta 55166, Indonesia \\ *e-mail: muhammad-sholeh@kemenperin.go.id
}

\begin{tabular}{l}
\hline INFO ARTIKEL \\
\hline Sejarah artikel: \\
Diterima: \\
2 Maret 2018 \\
Direvisi: \\
20 Juni 2018 \\
Diterbitkan: \\
28 Juni 2018 \\
\end{tabular}

\section{Kata kunci:}

kulit sintetis;

polivinil klorida;

dioktil ftalat;

poliuretan

\begin{abstract}
ABSTRAK
Penelitian ini bertujuan untuk mengetahui pengaruh kadar dioktil ftalat (DOP) terhadap sifat fisis dan mekanis kulit sintetis berbahan baku polivinil klorida (PVC). Kulit sintetis dibuat dari bahan resin PVC jenis emulsi dengan penambahan bahan aditif DOP sebagai pemlastis, $\mathrm{BaCd}$ sebagai penstabil, dan $\mathrm{CaCO}_{3}$ sebagai bahan pengisi, serta pigmen untuk pewarna lapisan atas. Kulit sintetis dibuat dengan 4 lapisan, yaitu lapisan poliuretan (PU), lapisan atas, lapisan dasar, dan kain penguat twill weave. Lapisan PU ditambahkan untuk memberikan sifat tahan abrasi, fleksibilitas tinggi, dan tahan pengusangan. Untuk membuat permukaan menyerupai kulit asli digunakan kertas embos. Pada penelitian ini DOP divariasi jumlah penambahannya pada lapisan atas berturut-turut 45, 50, 55, 60, dan 65 bagian. Ketebalan lapisan PU 0,1 mm, lapisan atas 0,6 mm, lapisan dasar 0,1 mm, dan kain penguat $0,3 \mathrm{~mm}$. Kulit sintetis hasil percobaan diuji sifat-sifat fisis dan mekanisnya meliputi kekuatan tarik, kemuluran, ketahanan sobek, ketahanan rekat, ketahanan luntur warna terhadap gosokan, ketahanan terhadap pelekatan, ketahanan terhadap temperatur rendah, dan ketahanan terhadap pengusangan. Kulit sintetis yang mempunyai sifat fisis dan mekanis yang optimal adalah kulit sintetis yang mengandung DOP 55 bagian pada lapisan atas.
\end{abstract}

Keywords:

synthetic leather; polyvinyl chloride; dioctyl phtalate; polyurethane

\begin{abstract}
The aim of this research was to investigate the effect of dioctyl phtalate (DOP) on physical and mechanical properties of synthetic leather made from polyvinyl chloride $(P V C)$. The leather was made from emulsion of $P V C$ resin by addition of additives such as dioctyl phtalate (DOP) as plasticizer, $\mathrm{BaCd}$ as stabilizer, $\mathrm{CaCO}_{3}$ as filler, and pigment as top coat coloring agent. Syntetic leather was made in four layers, those are polyurethane (PU) coat, top coat, base coat, and twill weave fabric. PU coat was added to give abrasion resistant, high flexibility, and aging resistant. Emboss paper was used to make the surface looked like natural leather. DOP was varied at top coat from 45, 50, 55, 60, until 65 part. The thickness of each layers were: $0.1 \mathrm{~mm}$ (PU coat), $0.6 \mathrm{~mm}$ (top coat), $0.1 \mathrm{~mm}$ (base coat), and $0.3 \mathrm{~mm}$ (fabric). Mechanical and physical properties of the synthetic leather such as tensile strength, elongation, resistance to tearing, resistance to peeling, resistance to crocking by rubbing, resistance to printing, resistance to low temperature, and resistance to aging were tested. Synthetic leather with 55 part of DOP was found to give the optimum physical and mechanical properties.
\end{abstract}

\section{Pendahuluan}

Industri lembaran plastik khususnya lembaran kulit sintetis telah berkembang pesat sehubungan dengan peningkatan permintaan bahan sandang dan perabot rumah tangga seperti jaket, ikat pinggang, sepatu, tas, koper, kursi sofa, jok mobil, dan sebagainya, yang sulit dipenuhi oleh bahan baku kulit asli karena terbatasnya ketersediaan kulit. Selain terbatasnya bahan baku kulit, harga produk kulit yang relatif lebih mahal dan isu 
kerusakan lingkungan sebagai dampak kegiatan industri penyamakan kulit juga ikut mempopulerkan produk berbahan kulit sintetis.

Mengingat fungsinya sebagai bahan substitusi kulit, diharapkan kulit sintetis mempunyai kenampakan dan sifat-sifat fisis yang mendekati kulit asli, disamping harganya relatif lebih murah daripada kulit asli sehingga terjangkau oleh lapisan masyarakat menengah ke bawah.

Kulit sintetis umumnya terdiri atas lapisan atas/top coat, lapisan tengah/middle coat (bisa ada bisa tidak ada), lapisan dasar/base coat, dan kain penguat (Kinge et al., 2013; Maia et al., 2017). Lapisan atas dibuat sedemikian rupa sehingga menyerupai permukaan kulit asli.

Tahapan umum produksi kulit sintetis meliputi pelapisan kompon resin di atas kertas embos, pengeringan atau pematangan lapisan kompon, pelapisan perekat ke atas lapisan resin yang telah kering atau matang, pelapisan serat penguat ke atas perekat, lalu melepaskan kertas embos dari kulit sintetis yang diperoleh (Suto et al., 2012).

Pembuatan kulit sintetis dapat menggunakan bahan baku polimer beragam, antara lain PVC (Musthofa et al., 1997), PU, poliamida (Liu et al., 2015; Qiang et al., 2017; Roh et al., 2013), akrilik, atau polyester (Ho, 2015). Basis polimer perlu ditambahkan bahan pembantu seperti pemlastis, penstabil, bahan pengisi, pigmen serta bahan penguat untuk mendapatkan kulit sintetis dengan sifat fisis dan mekanis yang diinginkan.

PVC adalah polimer termoplastik yang berstruktur amorf. PVC tidak dapat diproses tanpa penambahan aditif karena memiliki stabilitas termal yang rendah dan viskositas lelehan yang tinggi. Namun dengan penambahan berbagai aditif (selanjutnya disebut kompon), cakupan sifat produk akhir yang luas dapat dicapai. Ini yang menjadikan PVC menjadi salah satu polimer yang paling banyak dipakai, termasuk untuk pembuatan kulit sintetis (Akovali et al., 2012). Keunggulan PVC sebagai bahan kulit sintetis antara lain: murah, ketahanan yang bagus terhadap minyak, pelarut, dan abrasi, serta mudah dikompon dengan berbagai aditif. Kelemahan PVC yaitu cenderung rendah ketahanan termalnya (Balkose et al., 2008).

Agar PVC dapat bersifat fleksibel (tidak kaku) maka pada pembuatan kulit sintetis ditambahkan pemlastis. Bahan paling banyak dipakai untuk pemlastis adalah DOP. Lima langkah yang terlibat dalam penggabungan DOP ke dalam PVC antara lain (1) Langkah adsorpsi, yaitu pemlastis dicampur ke dalam resin PVC, (2) langkah adhesi, yaitu pemlastis masuk dan mengembangkan partikel resin, (3) langkah absorpsi, yaitu gugus polar di rantai PVC lepas satu dengan yang lain, (4) langkah plastisasi intermolekuler, yaitu gugus polar pemlastis berinteraksi dengan gugus polar polimer, (5) langkah plastisasi intramolekuler, yaitu struktur resin terbentuk ulang dengan retensi penuh dari pemlastis (Reinecke et al., 2011).

PU memiliki sifat seperti elastomer. Pelapisan kulit sintetis dengan PU dapat meningkatkan ketahanan kulit sintetis terhadap cuaca dan fleksibilitas pada suhu rendah (Akovali et al., 2012; Chen et al., 2010). Coating PU dapat dilakukan dengan metode kering, basah, dan kombinasi keduanya. Metode kering dilakukan dengan cara melapisi lembaran pelepas (release sheet) dengan $\mathrm{PU}$, mengeringkan PU dengan pemanasan, melapisi PU yang telah matang dengan perekat, melaminasi lembaran tekstil ke PU yang telah diberi perekat, mematangkan perekat, lalu melepaskan lembaran pelepas (Park et al., 2017).

Metode basah dilakukan dengan cara mencelupkan tekstil ke dalam larutan resin poliuretan, mengkoagulasikan resin, melapisi poliuretan ke atas tekstil dan mengkoagulasikan poliuretan kembali, mencuci sisa pelarut yang menempel, lalu mengeringkan kulit sintetis yang diperoleh (Park et al., 2017). Metode kombinasi menggunakan kulit sintetis hasil metode basah sebagai lembaran tekstil yang diaplikasikan ke metode kering.

Pembuatan kulit sintetis memerlukan formula dan kondisi operasi yang tepat agar hasil yang diperoleh memuaskan baik segi kenampakan, kekuatan, maupun daya tahannya. Produk barang jadi dengan bahan dasar kulit sintetis yang dijumpai di pasaran, kualitasnya sebagian mengecewakan karena mudah mengelupas dan permukaannya retak-retak.

Hosseini (2013) melakukan studi pengaruh DOP dan perubahan densitas pada sifat fisis dan mekanis komposit serbuk kayu/PVC. Hasil yang didapatkan yaitu pada kadar DOP yang semakin rendah dan densitas yang semakin tinggi, kekerasan dan kekuatan tarik meningkat dan penyerapan air berkurang. Balkose et al. (2008) mempelajari pengaruh variasi minyak biji jarak terepoksidasi dan DOP pada ketahanan termal PVC plastigel. Hasil penelitian menunjukkan bahwa DOP sebagian dapat disubstitusi oleh minyak biji jarak terepoksidasi tanpa menurunkan kualitas plastigel.

Nouranian et al. (2007) melaporkan faktor-faktor yang mempengaruhi kekuatan rekat lapisan PU dengan lapisan PVC antara lain jenis PU, suhu fusi PVC, tipe PVC, dan kadar pemlastis. Penelitian ini bertujuan untuk mendapatkan kadar DOP optimum pada lapisan top coat untuk pembuatan lembaran kulit sintetis PVC.

\section{Metode}

Bahan-bahan yang digunakan pada penelitian ini adalah: resin PVC jenis emulsi, PU, DOP sebagai pemlastis, $\mathrm{BaCd}$ sebagai penstabil, $\mathrm{CaCO}_{3}$ sebagai bahan pengisi, pigmen untuk pewarna lapisan atas, kertas embos, kain penguat twill weave, dan es kering. Peralatan yang digunakan meliputi: mixer, rol/pisau untuk coating, oven, alat uji kekuatan tarik, alat uji crocking, dan low-temperature tester.

Penelitian dilakukan melalui 3 tahapan, yaitu: pembuatan kulit sintetis, pengujian kulit sintetis, dan analisis hasil uji yang diperoleh. Kulit sintetis dibuat dengan 4 lapisan (Gambar 1), yaitu: lapisan PU $(0,1 \mathrm{~cm})$, lapisan atas $(0,6 \mathrm{~cm})$, lapisan dasar $(0,1 \mathrm{~cm})$, dan lapisan kain penguat $(0,3 \mathrm{~cm})$. Formulasi kompon untuk lapisan atas yaitu PVC 100 phr (part per hundred resin), DOP $\left(45,50,55,60\right.$, dan 65 phr), $\mathrm{BaCd} 5 \mathrm{phr}, \mathrm{CaCO}_{3} 10 \mathrm{phr}$, dan pigmen 1 phr. Lapisan dasar terdiri atas PVC 100 phr, DOP $50 \mathrm{phr}$, dan BaCd 5 phr. Perlakuan utama hanya pada kompon untuk lapisan atas saja, sedangkan pada lapisan dasar DOP tetap. Pengujian kulit sintetis dilakukan sebanyak tiga ulangan. 
Proses pembuatan kulit sintetis diawali dengan komponding lapisan atas dan lapisan dasar dengan menggunakan mixer. Kertas embos pertama-tama dilapisi dengan kompon PU setebal 0,1 mm lalu dioven pada suhu $140{ }^{\circ} \mathrm{C}$ selama 2 menit. Lapisan kedua yaitu top coat (lapisan atas) setebal $0,6 \mathrm{~mm}$ dioven pada $150^{\circ} \mathrm{C}$ selama 4 menit. Lapisan ketiga yaitu base coat (lapisan dasar) setebal $0,1 \mathrm{~mm}$ ditutup dengan kain penguat tipe twill weave lalu dioven pada $180{ }^{\circ} \mathrm{C}$ selama 2 menit. Terakhir dilakukan pelepasan kertas embos dari kulit sintetis.

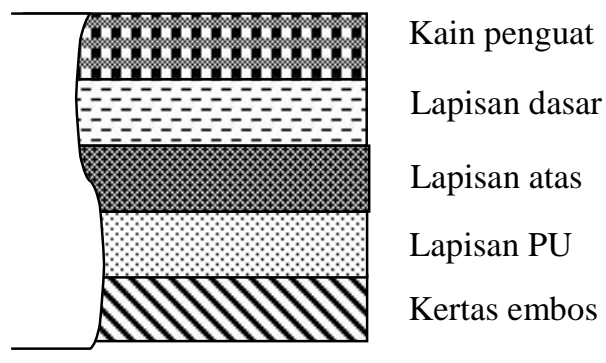

Gambar 1. Lapisan pada proses pembuatan kulit sintetis.

Hasil kulit sintetis yang diperoleh diuji kualitasnya meliputi kekuatan tarik, kemuluran, ketahanan sobek, ketahanan rekat, ketahanan luntur warna terhadap gosokan, ketahanan terhadap pelekatan, ketahanan terhadap temperatur rendah, dan ketahanan terhadap pengusangan sesuai syarat JIS K 6772 (JIS, 1994). Pengujian dilakukan pengulangan sebanyak tiga kali.

Uji kekuatan tarik dan kemuluran dilakukan dengan membuat cuplikan 3 buah arah melintang dan 3 buah arah membujur dengan ukuran panjang $250 \mathrm{~mm}$ dan lebar $30 \mathrm{~mm}$. Cuplikan ditarik dengan alat uji kekuatan tarik pada kecepatan $200 \mathrm{~mm} /$ menit.

Uji kekuatan sobek dilakukan dengan membuat cuplikan 3 buah arah melintang dan 3 buah arah membujur dengan ukuran panjang $150 \mathrm{~mm}$ dan lebar 40 $\mathrm{mm}$. Cuplikan dibelah sepanjang $75 \mathrm{~mm}$ dari tepi lalu ditarik dengan alat uji kekuatan tarik pada kecepatan 200 $\mathrm{mm} / \mathrm{menit}$

Uji ketahanan luntur warna terhadap gosokan dilakukan pada 6 buah cuplikan dengan ukuran lebar 30 $\mathrm{mm}$ dan panjang $220 \mathrm{~mm}$ (3 buah cuplikan untuk penggosokan kering dan 3 buah cuplikan untuk penggosokan basah). Penggosokan dilakukan dengan crock meter pada kulit sintetis sebanyak 100 kali gosokan lalu dievaluasi dengan membaca skala noda.

Uji ketahanan terhadap pelekatan dikerjakan dengan 6 buah cuplikan berukuran lebar $60 \mathrm{~mm}$ dan panjang 90 $\mathrm{mm}$. Dua buah cuplikan diletakkan berhadapan dengan 2 permukaan atas yang saling menempel, diletakkan di antara 2 pelat kaca, lalu diletakkan beban dengan berat 3 $\mathrm{kg}$ diatas kaca, kemudian dimasukkan ke dalam oven pada suhu $(70 \pm 2)^{\circ} \mathrm{C}$ selama 24 jam. Contoh diambil dari oven, dan dibiarkan pada suhu kamar selama 1 jam. Dua contoh dipisahkan lalu diperiksa apakah terjadi kerusakan pada permukaan kulit sintetis.

Uji ketahanan terhadap temperatur rendah dilakukan dengan merendam cuplikan di dalam es kering selama 5 menit di dalam low temperature tester sebanyak 3 buah arah melintang dan 3 buah arah membujur, lalu dilipat menjadi 2 dan dijatuhi beban dari jarak $50 \mathrm{~mm}$. Cuplikan diperiksa terhadap adanya keretakan pada lipatan.

Uji ketahanan terhadap pengusangan dilakukan dengan cuplikan 3 buah arah melintang dan 3 buah arah membujur. Cuplikan dimasukkan ke dalam oven dengan suhu $(100 \pm 2)^{\circ} \mathrm{C}$ selama 24 jam. Setelah dikeluarkan, cuplikan diperlakukan seperti pada uji ketahanan terhadap suhu dingin.

Uji kekuatan rekat dilakukan dengan membuat cuplikan 3 buah arah melintang dan 3 buah arah membujur dengan ukuran panjang $150 \mathrm{~mm}$ dan lebar 30 $\mathrm{mm}$. Lapisan PVC dengan kain penguat dipisahkan sepanjang $50 \mathrm{~mm}$ lalu ditarik dengan alat uji kekuatan tarik pada kecepatan 200 mm/menit.

\section{Hasil dan pembahasan}

\subsection{Kekuatan tarik}

Hasil uji kekuatan tarik yang disajikan pada Gambar 2 menunjukkan bahwa semakin besar bagian DOP, kekuatan tarik kulit sintetis cenderung naik pada kadar pemlastis yang rendah sampai dengan 55 bagian, selanjutnya turun. Hal ini disebabkan oleh DOP (Gambar 3) merupakan pemlastis yang mempunyai sifat menurunkan kekakuan PVC sehingga kekuatan tariknya turun sebanding dengan bagian DOP.

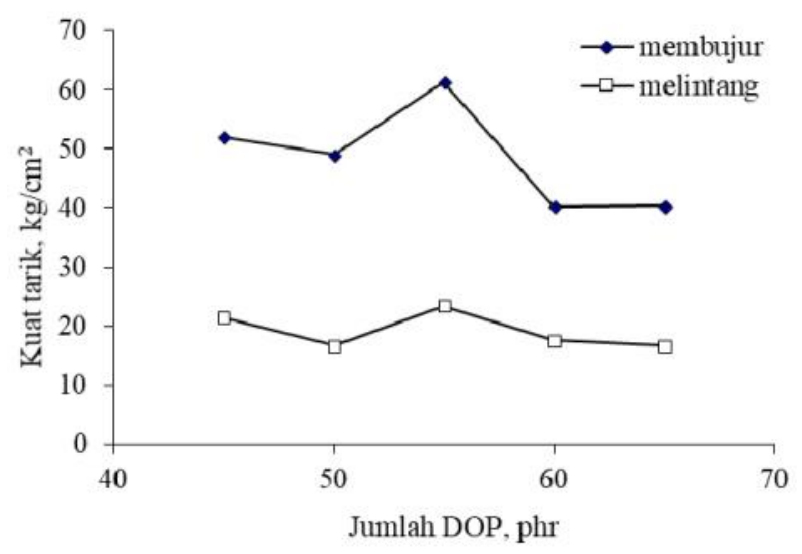

Gambar 2. Grafik hubungan jumlah pemlastis DOP dalam kompon lapisan atas terhadap kekuatan tarik kulit sintesis.

Hosseini (2013) mendapatkan kecenderungan hasil yang sama pada kadar DOP $80-100 \%$ berat PVC. Demikian pula kecenderungan data yang diperoleh Yongqin (2004) pada rasio DOP/DBP $=1 / 1$. Menurut Wypych (2004), pemlastis bertindak sebagai pelumas mengisi ruang kosong antar rantai polimer, sehingga bila ada gaya tarik yang bekerja maka rantai polimer akan tergelincir satu sama lain. Efek DOP terhadap struktur antar rantai PVC terlihat pada Gambar 4.

Kekuatan tarik arah membujur lebih tinggi daripada kekuatan tarik arah melintang. Hal ini dipengaruhi oleh struktur kain penguat twill weave yang lebih kuat di arah membujur. Hasil kuat tarik tertinggi diperoleh pada kadar DOP sebesar 55 bagian dengan nilai $61,38 \mathrm{~kg} / \mathrm{cm}^{2}$ untuk kuat tarik membujur dan $23,37 \mathrm{~kg} / \mathrm{cm}^{2}$ untuk kuat tarik melintang. 


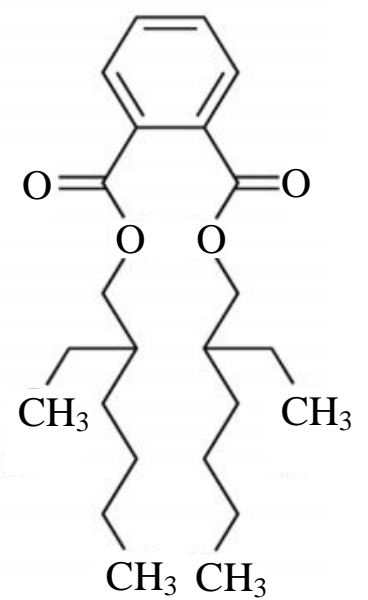

Gambar 3. Struktur molekul dioktil ftalat.

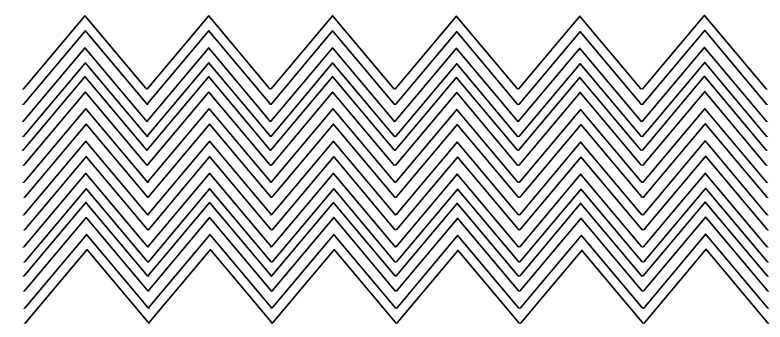

(a)

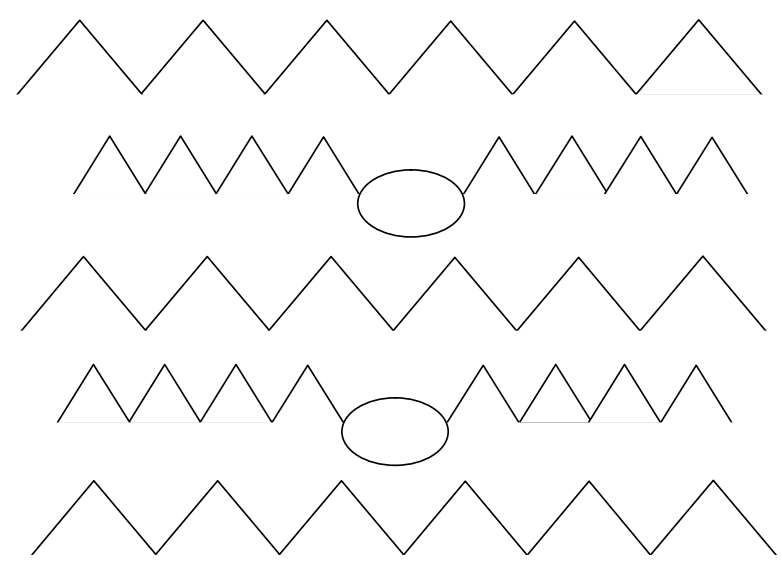

(b)

Gambar 4. (a) Susunan rantai PVC tanpa DOP; (b) susunan rantai PVC dengan DOP (Arakh, 2013).

\subsection{Kemuluran}

Kemuluran kulit sintetis dipengaruhi juga oleh kadar DOP. Dari Gambar 5 terlihat bahwa kemuluran kulit sintetis meningkat sebanding dengan bagian DOP. Ini terjadi karena DOP yang ditambahkan memberikan fleksibilitas pada PVC. Menurut Wypych (2004), pemlastis mengurangi gaya kohesi antar molekul polimer. DOP yang mengisi ruang antar rantai polimer PVC memudahkan rantai bergerak dan bergeser satu sama lain.

Sama halnya dengan kekuatan tarik, perbedaan kemuluran arah membujur dengan melintang dipengaruhi oleh struktur kain penguat twill weave. Kemuluran tertinggi diperoleh pada kadar DOP sebesar 55 bagian dengan nilai $20 \%$ untuk kemuluran membujur, sedangkan untuk kemuluran melintang pada kadar DOP sebesar 55 dan 65 bagian dengan nilai 30\%.

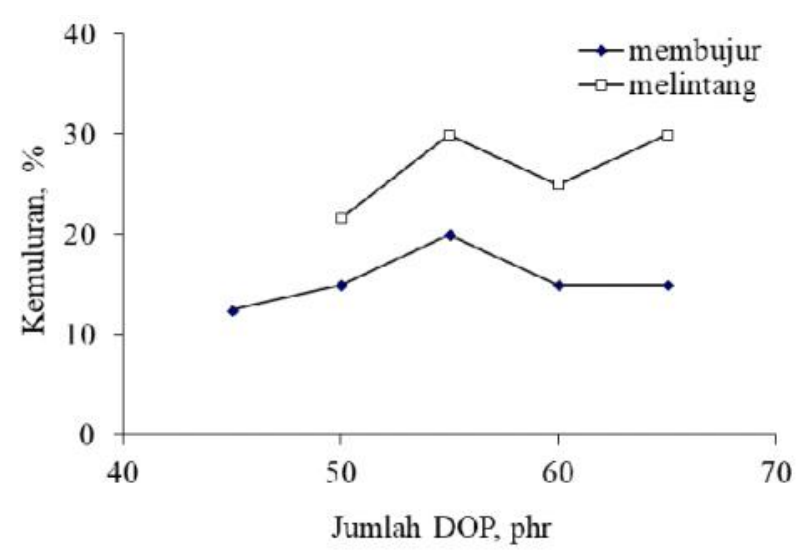

Gambar 5. Grafik hubungan jumlah pemlastis DOP dalam kompon lapisan atas terhadap kemuluran kulit sintetis.

\subsection{Ketahanan sobek}

Semakin banyak DOP yang ditambahkan cenderung menurunkan sifat ketahanan sobek (Gambar 6), hal ini disebabkan oleh semakin banyak jumlah DOP yang ditambahkan kulit sintetis makin lemas sehingga kekuatan yang diperlukan untuk menyobek semakin kecil. Saat kompon dipanasi, molekul-molekul pemlastis mendifusi ke dalam polimer dan melemahkan interaksi polimer dengan polimer.

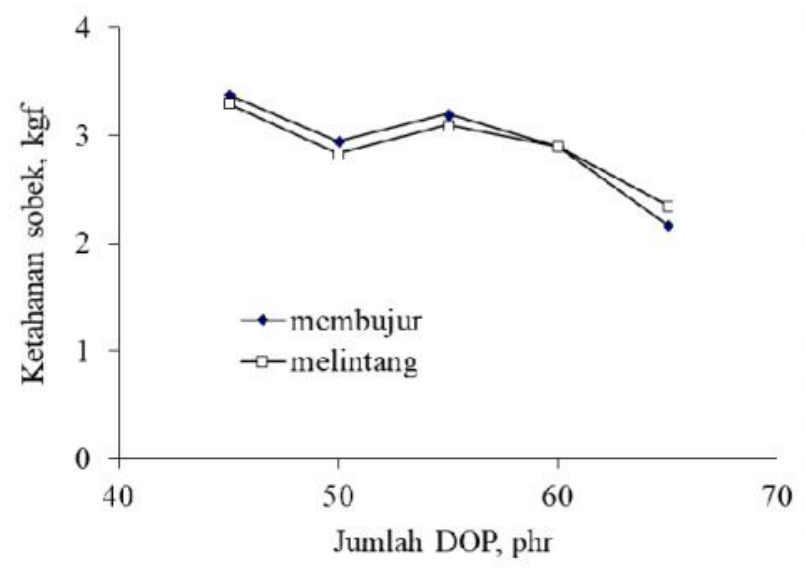

Gambar 6. Grafik hubungan jumlah pemlastis DOP dalam kompon lapisan atas dengan ketahanan sobek kulit sintetis.

Disini molekul pemlastis bertindak sebagai tameng untuk mengurangi gaya Van der Waals antar rantai polimer dan mencegah pembentukan jaringan yang kaku. Akibatnya rantai polimer dapat bergerak dengan mudah yang menghasilkan peningkatan kelunakan, fleksibilitas, dan kemuluran (Daniels et al., 2005).

Dari Gambar 6 terlihat bahwa ketahanan sobek tertinggi diperoleh pada penambahan DOP 45 bagian 
dengan nilai 3,38 kgf untuk ketahanan sobek membujur dan 3,30 kgf untuk ketahanan melintang.

\subsection{Ketahanan luntur warna}

Ketahanan luntur warna terhadap gosokan baik secara kering maupun basah (Tabel 1) menunjukkan hasil yang bagus dengan minimal nilai sebesar 4,5. Hal ini disebabkan oleh lapisan PU menutup atau menghalangi lunturnya warna dari permukaan lapisan atas (top coat) pada saat terjadi gosokan (Akovali et al., 2012).

\subsection{Ketahanan terhadap pelekatan}

Variasi jumlah penambahan DOP secara visual terlihat cenderung kurang berpengaruh pada sifat ketahanan terhadap pelekatan. Pada Tabel 1 terlihat bahwa hasilnya baik dengan tidak nampaknya cacat pada permukaan kulit sintetis.

\subsection{Ketahanan terhadap temperatur rendah}

Ketahanan terhadap temperatur rendah (Tabel 1) terlihat bahwa seluruh variasi penambahan DOP menunjukkan hasil yang baik (tidak retak setelah dibengkuk). Hal ini disebabkan adanya lapisan PU yang memberikan keunggulan fleksibilitas temperatur rendah (Chen et al., 2010). Hasil senada diperoleh oleh Shen et al. (2017). Menurut Akovali et al. (2012), pelapisan kulit sintetis dengan PU dapat meningkatkan ketahanan kulit sintetis terhadap cuaca dan fleksibilitas pada suhu rendah.

Tabel 1.

$\underline{\text { Rekapitulasi hasil uji sifat fisis dan mekanis kulit sintetis }}$

\begin{tabular}{lllllll}
\hline \multirow{2}{*}{ Jenis uji } & & \multicolumn{2}{l}{ Variasi DOP $(\mathrm{phr})$} & & & \\
\cline { 2 - 6 } & & 45 & 50 & 55 & 60 & 65 \\
\hline Ketahanan rekat; kg & Membujur & - & - & 3,25 & - & - \\
& Melintang & - & - & 3,15 & - & - \\
Ketahanan luntur warna terhadap & Kering & $5,0 / 5,0$ & $4,5 / 5,0$ & $5,0 / 5,0$ & $4,0 / 5,0$ & $5,0 / 5,0$ \\
gosokan & Basah & $4,5 / 5,0$ & $5,0 / 5,0$ & $4,5 / 5,0$ & $5,0 / 5,0$ & $5,0 / 5,0$ \\
Ketahanan terhadap pelekatan & & tidak & tidak & tidak & tidak & tidak \\
& & cacat & cacat & cacat & cacat & cacat \\
Ketahanan terhadap temperature rendah & tidak & tidak & tidak & tidak & tidak \\
& & retak & retak & retak & retak & retak \\
Ketahanan terhadap pengusangak & & tidak & tidak & tidak & tidak & tidak \\
& & cacat & cacat & cacat & cacat & cacat \\
\hline
\end{tabular}

\subsection{Ketahanan terhadap pengusangan}

Ketahanan terhadap pengusangan (Tabel 1) terlihat bahwa seluruh variasi penambahan DOP menunjukkan hasil yang baik (tidak retak setelah diusangkan). Lapisan PU mampu mencegah terjadinya kerusakan pada permukaan kulit sintetis.

\subsection{Ketahanan rekat}

Ketahanan rekat antara lapisan polimer dengan kain penguat diasumsikan tidak dipengaruhi oleh variasi kadar DOP. Hal ini didasarkan bahwa variasi DOP dilakukan pada lapisan atas, sedangkan yang melekat pada kain penguat adalah lapisan dasar. Diperoleh ketahanan rekat membujur sebesar 3,25 $\mathrm{kgf}$ dan melintang sebesar 3,15 kgf.

Dari nilai parameter uji kualitas kulit sintetis yang diperoleh, perlu dilakukan kompromi antara berbagai kecenderungan nilai yang didapatkan pada kriteria kekuatan tarik, kemuluran, dan ketahanan sobek. Kadar DOP yang rendah menguntungkan dari sisi kuat tarik dan ketahanan sobeknya, namun kulit sintetis yang dihasilkan menjadi kaku. Kadar DOP yang tinggi menguntungkan dari sisi kemulurannya karena kulit sintetis menjadi fleksibel dan mudah dibentuk, meskipun dipertimbangkan juga batas fleksibilitasnya sesuai aplikasi dari kulit sintetis tersebut. Namun kadar DOP yang tinggi menyebabkan kuat tarik dan ketahanan sobeknya tidak memuaskan. Kadar DOP yang memberikan hasil kompromi terbaik yaitu 55 bagian.

\section{Kesimpulan}

Pembuatan kulit sintetis berbahan baku PVC dengan penggunaan jumlah DOP 55 phr memberikan hasil kulit sintetis yang terbaik. Penggunaan lapisan PU di atas top coat, dapat memberikan keunggulan sifat tahan abrasi, fleksibilitas tinggi, dan tahan pengusangan.

\section{Ucapan terima kasih}

Penulis mengucapkan terima kasih kepada Kepala Balai Besar Kulit, Karet, dan Plastik yang telah memfasilitasi dilaksanakannya penelitian ini.

\section{Daftar pustaka}

Akovali, G., Banerjee, B., Sen, A.K., Setua, D.K., 2012. Advances in polymer coated textiles. Smithers Rapra.

Arakh, A., 2013. Plasticizer, Institute of Chemical Technology.

Balkose, D., Egbuchunam, T.O., Okieimen, F.E., 2008. Formulation and properties evaluation of PVC/(dioctyl phthalate)/(epoxidized rubber seed oil) plastigels. J. Vinyl Addit. Technol. 65-72. https://doi.org/10.1002/vnl 
Chen, Y., Yan, L., Wang, R., Fan, H., Zhang, Q., 2010. Antimicrobial polyurethane synthetic leather coating with In-situ generated Nano-TiO2. Fibers Polym. 11, 689-694. https://doi.org/10.1007/s12221-010-0689-1

Daniels, C.A., Summers, J.W., Wilkes, C.E., 2005. PVC handbook. Hanser Gardner Publication, Ohio.

Ho, K.C., 2015. Improvement on stain resistance of synthetic leather by plasma treatment under atmospheric pressure. The Hong Kong Polytechnic University.

Hosseini, S.B., 2013. Effects of Dioctyl phthalate and density changes on the physical and mechanical properties of woodflour/PVC composites. J. Indian Acad. Wood Sci. 10, 22-25. https://doi.org/10.1007/s13196-013-0088-5

JIS, 1994. JIS K 6772:1994 Polyvinylchloride coated fabric.

Kinge, A.P., Landage, S.M., Wasif, A.I., 2013. Nonwoven for artificial leather. Int. J. Adv. Res. Eng. Appl. Sci. 2, 18-33.

Liu, R., Chen, Y., Fan, H., 2015. Design, characterization, dyeing properties, and application of acid-dyeable polyurethane in the manufacture of microfiber synthetic leather. Fibers Polym. 16, 19701980. https://doi.org/10.1007/s12221-015-5024-4

Maia, I., Santos, J., Abreu, M.J., Miranda, T., Carneiro, N., Soares, G.M.B., 2017. PVC-based synthetic leather to provide more comfortable and sustainable vehicles. IOP Conf. Ser. Mater. Sci. Eng. 254, 0-6. https://doi.org/10.1088/1757-899X/254/12/122006

Musthofa, H., Nadilah, S., Suprapto, S., 1997. Penelitian pemanfaatan parafinic oil sebagai bahan plastilizer seconder dalam pembuatan kulit imitasi untuk atasan sepatu. Maj. Kulit, Karet dan Plast. 12, 70-78.
Nouranian, S., Garmabi, H., Mohammadi, N., 2007. Taguchi-based optimization of adhesion of polyurethane to plasticized poly(vinyl chloride) in synthetic leather. J. Adhes. Sci. Technol. 21, 705724. https://doi.org/10.1163/156856107781362644

Park, E.S., Kim, J.J., Min, D.J., Shin, D.W., 2017. Polyurethane synthetic leather and polyurethne film comprising sucrose and method for preparing the same. EP 3135809 A1.

Qiang, T., Wang, Y., Wang, L., Zheng, Y., Zhang, F., Zheng, S., 2017. Study on the effect of the sanitary properties of microfiber synthetic leather base by using a filling agent. Text. Res. J. 4051751770019. https://doi.org/10.1177/0040517517700194

Reinecke, H., Navarro, R., Pérez, M., 2011. Plasticizer. Encycl. Polym. Sci. Technol. https://doi.org/10.1002/0471440264.pst245.pub2

Roh, E.K., Oh, K.W., Kim, S.H., 2013. Classification of synthetic polyurethane leather by mechanical properties according to consumers' preference for fashion items. Fibers Polym. 14, 1731-1738. https://doi.org/10.1007/s12221-013-1731-X

Shen, M., Niu, X., Wang, G., 2017. Bio-based waterborne polyurethane dispersion evaluation for synthetic leather applications. PU Mag. 14, 2-8.

Suto, K., Kawagoe, Y., Watanabe, H., Kubota, T., Matsuraida, K., 2012. composition for matte layer formation, release sheet using the same, and synthetic leather produced using said release sheet. US 8137789 B2

Wypych, G., 2004. Handbook of plasticizer. Chem Tec Publishing, Ontario.

Yongqin, W.S.H., 2004. Comparison of the influence of dop and dbp on the property of PVC paste resin. Eng. Plast. Appl. 